\title{
Diversity of Love Relationship in Janette Oke's Fictions
}

\author{
Sayyed Ali Mirenayat ${ }^{1, *}$, Elaheh Soofastaei ${ }^{2}$ \\ Faculty of Modern Languages and Communication \\ Universiti Putra Malaysia \\ *E-mail address: ali.mirenayat@yahoo.com¹ ${ }^{1}$, ela.soofastaei@yahoo.com²
}

Keywords: Gallantry; Trial Love; Courtly Love; Marriage; Pure Romantic Love

\begin{abstract}
Love is used in different ways in literature. The treatment of love in the love stories of Janette Oke are nearly similar and all show the roles that love plays in life of people and how deal with it. Her novels are among the finest works in Canadian literature without whom the world of Canadian literature would be dark and empty. Love is the eventual weakness, but philosophy, religion and art during time have portrayed it in its place as a way to a higher level of being beyond the pain and transformation of every day. This paper points out to different kinds of love relationship in Oke's fictions.
\end{abstract}

\section{INTRODUCTION}

The history of different love is not similar. Each love has its own history. It has a start and an end and between these a procedure of waxing and waning within which the significance of the pattern of distinctions changes. It is then often proposed in the literature that the start of a love affair, before the love has been granted any social definitely, depends above all on satisfaction. Love, in order to be differentiated from the communication in which it may be camouflaged, must be able to take on the function of a comprehensive symbolic medium and as a result becomes subject to a further set of conditions, in the context of which endeavors to satisfy can only figure as foreplay. Things become even more compound if the difference between true and pretended love is treated in such a behavior that one distinguishes the latter structure in terms of its simulation or dissimulation. A double camouflage must therefore be deemed: the simulation and dissimulation of love. Both can, especially if working in carriage, throw up adequate hurdles to begin a love affair. The paradox notwithstanding stays dependent on the fact that love is a procedure and that it donates a temporal condition on all information. There are three kinds of love in Janette Oke's romantic novels including unselfish love, logical love, and romantic love. Romantic love includes gallantry, pure romantic love, trial marriage and courtly love that I discuss in this paper.

\section{GALLANTRY}

The concept of 'gallantry' uses this goal for a certain traditional era. Under the mask of gallantry, courting can happen in the existence of the third parties. Gallant behavior supplies adaptive connections both to the closeness and also to sociability and can join distinctions in rank. It searches for only to give pleasure, without by so doing implying oneself and the others. According to Love's Long Journey and Love's Abiding Joy, gallantry is possible in a social situation and yet at the same time emerges to be an educating, socializing, and civilizing result. In the things, it involves and the linguistic forms it takes, gallantry keeps a novelistic and idealistic meaning. As a result of this double goal, it gets difficult to decode what a person's behavior shows and to know true and real love. It gives rise to an attention in unmasking the real goal of behavior, a procedure in which the art of love is both educated and revealed.

Gallantry is subject to refusal and mockery, and the duty of reintegrating love and society hands over a new form: the moral legitimation of emotion. The distinction between two forms of 
loving a friend is the distinction between two forms of disinterestedness. If one selects to make the distinction the point of direction, any direction towards individuality of the other person is already prohibited from the beginning by that real selection. In a period when a need for direction toward individuality is already being invented at the level of socio-structural changes, it means that religion and morals become exterior. The gallantry practiced only in the aristocratic strata declined, as did the terminology that had been used to identify class-specific features. However, the characterizations included stayed simplifications for the accidentally and unimportant with which friends were sought out by letter writing, and the speed with which the closest of friendships improved, confirm to the fact that personal features were not all that important.

Friendships were not founded on features related to only the one friend as differentiated from all others. The asymmetry of internal experience and behavior involves the probability of expectation: one is able to orientate oneself towards the internal experience of the other person, if he has not really carries that anticipation, has not stated a desire of any kind and not responsible for ascription anything to himself. This is what is meant when in the concepts of love someone is encouraged to move beyond the call of the gallant task, or when mention is made of 'unspoken' agreement. It is as well what is experienced when lovers have no require trusting approaches for reading an agreement in order to perform in harmony the opposite of third parties. Love solves its own companion expressive difficulties in a totally remarkable behavior. Love can increase conversation and relationship by mostly doing without any conversation or communication.

\section{PURE ROMANTIC LOVE}

The problem of leaving the door open for marriages based on events that were no longer subject to regulation had become current in the course of alterations in the social framework and told further improvements of the symbolic medium of love. At this time, however, the only semantic relate available was love passion, which, while being open to enhancement with new themes, could not itself resolve the subject of steadiness. It was only possible to outbid it in terms of excessiveness and to proclaim that guiding a simple life was completely unintentional. The adoration was, however, to stay a particular happening which by no ways hidden everything that has since, in a sense no longer only connected to novels, been termed Romantic love. It is also evident in her novels.

Romantic love then had to suppose the duty of giving details the reason for the existence side by side of both happiness and unhappiness in marriage. In the course of the nineteenth century, the obstacles to a marriage based on Romantic love were taken down and therefore had a consequence on what was now seen and wished as Romantic. Love became the only lawful reason for the choice of a partner, and all those moments of passion that were intimidate, that jeopardized existence and put life and death in the equilibrium had to be filtered out. What remained was an institutionalized thought for enchanted passion and the supposition that this was a kind of test of one's eagerness to marry in addition to a guarantee of happiness of sorts. About Janette Oke's love stories; I believe that romantic love is the origin of the most extreme pleasures that life has to make a present. When a man and woman love each other with eagerness and interest and affection and imagination, there is something of immeasurable worth, to be unaware of which is an extremely misfortune to any person. I believe that; it is important that a social system should be as like to allow this delight, in spite of the fact that it can only be a component in life and not it's most important aim.

\section{TRIAL MARRIAGE AND COURTLY LOVE}

Janette Oke has not used trial marriage in her novels because she believes that this kind of marriage is unwisely and ineffectively. Courtly love is a classic literary genre that once ruled over as the most important and most experienced kind of literature. Love is an art to be trained in the courtly manner. It is trained only between a man and a woman who is not husband and wife and presented as ideal and above the territory of intercourse, and such relationships did not also exist in real life medieval marriages. It is interesting that relations of dependency are a foundation of both 
power and love. And dependency is also part of marital love, since a love relationship, can be seen as consisting of emotional and material exchanges, or mutual dependence. But Janette Oke has not also used courtly love in her novels.

The freedom to select the object of one's love set up with the help of self-constructed delusion, and these fictions were one after the other always seen through. It is only because of this original situation that the requirement comes from a principle which not only makes forms to be used to praise one's feeling, but is as well invented to regulate communication between two partners. The distinction of a double eventuality simulates the improvement of a special concept to which, if social relationships become unsteady, one can cling instead. It cannot be stressed enough on that the freedom to select someone to love applies to the extramarital relationships of married people. Unmarried girls were protected very successfully against temptation, and tempting them would have scarcely added to the glory of the hero. Freedom then began with marriage. In terms of its importance for the evolution of love concept, this meant above all the elision of a significant proof of love, that is to say the will to marry.

\section{LOVE: TRUE OR FALSE?}

However, exactly this two compels the distinction of true and false love; one is forced to scan one's endeavors to satisfy for information that refers to this second distinction till the receding of one's endeavors propose the first indications that true love is starting to decline. The love relationship step-by-step becomes unreliable. The fact that the beginning of a relationship is decided by a more or less traditional form of art of pleasing also means that one can begin on love without knowing that it is love. Especially in its oral regulation gallantry takes on a form that is not only orientated towards pleasing, but also hugs both true and false love; yet at the same time it as well includes a secret meaning if it is true love.

There, hurdles suppose the function of making love aware, and my further hurdles one of testing love. One may begin with a somewhat traditional friendship and the change of humors only to observe after a definite time that it is love. One can fall in love while the procedure of simulating love, get caught up in one's own gallantry and then neglect the suitable time to retreatment. One was afraid of coquettishness because it can immediately lend the relationship form of simulated love.

That the procedure finishes in lack of concern also means that the distinction between true and false love is now used to obtain entirely different information, i.e. in order to cool out the relationship and to keep away from emotional reactions which would no longer be appropriate. What is more, they show that the particular pattern of distinctions which have to be operated to gain especial information depends on the stage arrive at the procedure. At first, hope and worry and the others to true and false love, occur in the alteration from pleasing to love. The one distinction sets free the other from within itself without in this manner vanishing. The total frame of the concept of love discloses in time, as a result there can be no assert made of the principle that does not itself have a value and place in time. The procedure stays sovereign and determines the distinction it uses to get information. The principle, as a result, depends on an extremely intricate semantic architecture.

The distinction between true and false love, which is to be differentiated from the communication that may camouflage it, is based on the distinction between love and pleasure which sequentially serves to formulate an escalating distinction between anthropological self-referentiality on the one hand and social comprehension on the other. Or inversely, the socio-structurally resolute requirement for a more obvious disconnection of personal and social reflexivity is stated in the differentiation between pleasure and love, which in turn allows, with reference to pleasure, real and unreal modes of conduct to be discovered in love, a differentiation which thus tells each person's firm sensibility for information in accurate love affairs.

We can find attractiveness in Oke's novels. Attractive usually means a nice box of features which are favored and very sought-after on the character bazaar. What particularly makes a man or woman attractive depends on the style of the time, bodily and also mentally. If I want to compare nowadays' life with the life in the time of Oke's stories, in that time finding a partner was very 
difficult. The life style is very different that you don't meet many single partners easily. But in today's life, by going church, classes, clubs, and so on you will meet more people. In Love's Enduring Promise, both man and woman, Willie Lahaye and Missie, agree that bilateral attraction, reliable personality, and emotionally steadiness are the most important characteristics. However, both of them disagree about the significance of certain other characteristics, e.g. man value good looks more than woman and woman value good financial future and ambitiousness more than man. Oke has not used trial marriage and courtly love in her novels, because she believes that trial marriage is unwisely and ineffectively and living together and getting pregnant as ruses for getting someone to marry is injudicious.

\section{CONCLUSION}

In Janette Oke's novels, marriages are, to some extent, traditional and the wife is approximately dependent on her husband, with the newer forms of independent and interdependent relations, in which power and dependency are more identical, gender roles are more bisexual, and the self-improvement and self-government of each person is a central value. We can come to conclusion that in Oke's novels, there is a healthy love. The love relationship in her novels can be healthy love, because both male and female characters understand each other's needs without disregarding their requirements. Both sides understand that they can love each other while having different viewpoints and interests. Oke perfectly shows a classic way of loving others in her novels.

\section{References}

[1] Capellanus, Andreas, The Art of Courtly Love. New York: Columbia UP, 1990.

[2] Hammill, Faye. Canadian Literature. Edinburg UP, 2007.

[3] Kroller, Eva-Marie. The Cambridge Companion to Canadian Literature. Canada: Cambridge UP, 2004.

[4] Merton, Thomas. Love and Living. New York, 1979. Hardcourt Trade Publishers, 2002.

[5] Mirenayat, Sayyed Ali. The Treatment of Love in Janette Oke's Selected Novels. MA Diss, 2012.

[6] Savage, Dan. The Commitment: Love, Sex, Marriage and Family. Dutton Press, 2005.

[7] Schultz, James Alfred. Courtly Love, the Love of Courtliness, and the History of Sexuality. University of Chicago, 2006.

[8] Ward, Mary. The Literature of Love. Cambridge UP, 2006. 